\title{
(C) OPEN ACCESS \\ Patient activation intervention to facilitate participation in recovery after total knee replacement (MIME): a cluster randomised cross- over trial
}

\author{
Jo McDonall, ${ }^{\oplus}$ Richard de Steiger, ${ }^{\oplus 2}$ John Reynolds, ${ }^{\oplus 3}$ \\ Bernice Redley, ${ }^{\oplus 1}$ Patricia M Livingston, ${ }^{\oplus 4}$ Anastasia F Hutchinson, ${ }^{\odot 5}$ \\ Mari Botti ${ }^{\circ}$
}

\begin{abstract}
- Additional material is published online only. To view please visit the journal online (http://dx.doi.org/10.1136/ bmjqs-2018-008975).
\end{abstract}

For numbered affiliations see end of article.

\section{Correspondence to} Dr Jo McDonall, Faculty of Health, School of Nursing and Midwifery, Deakin University, Geelong, VIC 3220, Australia; jo.mcdonall@deakin.edu.au

Received 16 October 2018 Revised 15 March 2019 Accepted 18 March 2019 Published Online First 11 April 2019

\section{SLinked}

- http://dx.doi.org/10.1136/ bmjqs-2019-009571

\section{Check for updates}

(C) Author(s) (or their employer(s)) 2019. Re-use permitted under CC BY-NC. No commercial re-use. See rights and permissions. Published by BMJ.

To cite: McDonall J, de Steiger R, Reynolds J, et al. BMJ Qual Saf

2019;28:782-792.

\section{ABSTRACT}

Background Patient participation in care is a fundamental element of safe and high-quality healthcare with the potential to enhance health outcomes and improve patient satisfaction.

Objectives To test the efficacy of a clinician-facilitated, bedside multimedia (MyStay) intervention designed to support patient participation in their recovery after total knee replacement surgery. The primary outcome was patients' reported worst pain intensity on postoperative day 3. Secondary outcomes were patient activation, length of hospital stay, knee function and satisfaction with care.

Methods Unmasked, cluster randomised, four-period cross-over trial with a simultaneous process evaluation within in a large private, not-for-profit, metropolitan teaching hospital. Statistical analyses used linear mixed models with random effects for wards, cohorts within wards and patients within cohorts and fixed effects for treatment and period.

Results 241 patients were recruited between March 2014 and June 2015. Patients were admitted to intervention (104) or control (137) clusters. Intervention group patients reported significantly lower mean pain intensity scores on postoperative day 3 (6.1 vs 7.1, 95\% $\mathrm{Cl}-1.94$ to $-0.08, \mathrm{p}=0.04$ ). The percentages of patients who reported severe pain (score $\geq 7$ ) were $43.7 \%$ and $64.2 \%$ in the intervention and control groups, respectively $\left(\chi^{2}\right.$ 9.89, $p=0.002$; generalised linear mixed model Wald test, $p=0.05)$. Intervention group patients on average stayed in hospital one less day (5.3 vs 6.3, $95 \% \mathrm{Cl} 0.05$ to $1.94, p=0.04)$, reported higher activation ( $45.1 \%$ vs $27.1 \%$ at level 4 activation) ( $p=0.04$ ) and higher overall satisfaction with care $(9.3$ vs $8.6,95 \% \mathrm{Cl}$ 1.09 to $0.219, p=0.01$ ), and were more likely to refer family or friends to the health service $(9.3$ vs $8.7,95 \% \mathrm{Cl}$ 1.07 to $0.13, p=0.02$ )

Conclusion The clinician-facilitated, MyStay bedside multimedia intervention enhanced patients' activation and participation in their care after surgery; pain intensity and length of stay in hospital were reduced and patients were more satisfied with their care.

Trial registration ACTRN12614000340639 (http:// www.anzctr.org.au/default.aspx).

\section{INTRODUCTION}

Patient participation is recognised worldwide as a key element of quality healthcare. ${ }^{1-3}$ It is associated with positive outcomes for patients with chronic illness, ${ }^{4-6}$ but benefits of patient participation in acute care contexts remain less well described. In high acuity environments, barriers to participation include the brevity of interactions ${ }^{7}$ with multiple clinicians, ${ }^{89}$ patients' symptom burden, ${ }^{9-11}$ acuity, ${ }^{11}$ perceived knowledge related to their condition, ${ }^{812}{ }^{13}$ level of confidence ${ }^{14-16}$ and preference for participation. ${ }^{17-19}$ Yet overcoming these barriers will likely enhance recovery and patient experience overall. ${ }^{1420}$

The early postoperative period after total knee replacement surgery (TKR) involves a complex balance between recovery, rehabilitation and prevention of complications. TKR is performed to treat end-stage arthritis when other treatment methods have not improved patient symptoms. ${ }^{21}$ Achieving maximum benefit from this surgery is dependent on correct insertion and fixation of the prosthesis, restoration of alignment of the knee ${ }^{22}$ and early mobilisation of the knee joint to maximise range of movement. ${ }^{23}{ }^{24}$ Although a relatively common and successful procedure, TKR is considered one of the most painful, ${ }^{25}$ particularly in the early postoperative period. ${ }^{26}$ Patient participation in pain management, mobilisation and exercises may enhance recovery and prevent complications; however, activating patients to participate and work with the multidisciplinary team in order to benefit 
from the healthcare available to them ${ }^{16} 27$ is complex in acute environments. Simply equipping patients with information about ideal recovery without structured facilitation by clinicians is not sufficient. ${ }^{28}$ Innovative strategies are needed to assist patients to participate effectively in their care to the extent that is possible and preferred. Multimedia technology offers a potential platform for facilitating patient-clinician interactions because of its low burden, continuous availability and ease of use. There is evidence that multimedia plays an important role in preoperative delivery of information for patients undergoing surgery, ${ }^{29-31}$ but not for their postoperative recovery.

The study aimed to test whether the MyStay intervention, a clinician-facilitated multimedia programme designed to inform and assist patients to participate daily in their acute postoperative recovery, improved their recovery in terms of reduced pain intensity, reduced length of hospital stay, improved activation and function, and satisfaction with care received.

\section{METHODS}

\section{Trial design and participants}

The Multimedia Intervention for Managing patient Experience (MIME) study was an unmasked, cluster randomised, four-period cross-over trial and simultaneous process evaluation conducted in three acute, inpatient orthopaedic wards of a large private, not-forprofit, metropolitan teaching hospital in Melbourne, Australia. Wards rather than patients were randomised to minimise 'contamination' through any exchange of information between patients. Because the intervention was clinician-facilitated and delivered on portable devices, blinding was not feasible. The duration of each period ranged from 12 to 16 weeks and was determined by the number of participants required in each cohort. Patient-level data were collected to measure outcomes (figure 1). For pragmatic reasons, namely to minimise the resources required to coordinate the study simultaneously over several sites, a cluster randomised cross-over trial, with 'washout' intervals between the periods and cohorts, was favoured in contrast to a cluster randomised trial run simultaneously at several sites or a stepped-wedge design. The cross-over design also allowed for adjustment, if required, for any trend in pain management over the life of the trial. The full trial protocol, including sample size calculation, has been published previously. ${ }^{32}$

Patients were included if they were adults (aged $>18$ years) and had an elective admission for primary, unilateral, TKR surgery and excluded if they were cognitively impaired or lacked proficiency in English language such that it would interfere with informed consent or ability to complete questionnaires. Most patients $(79.6 \%)$ attended a standardised preoperative education session at the hospital 1 to 2 weeks prior to surgery and received information on how a TKR was performed, the possible risks and what to expect in the postoperative period.

\section{Primary outcome}

The primary outcome was patients' reported worst (dynamic) pain intensity score measured using the 11-point Numerical Rating Scale ${ }^{33}$ (NRS) on day 3 after surgery (where day 0 refers to the day of surgery). Patients were asked to choose a whole number between 0 and 10 that best described their worst pain in the previous 24 hours where 0 equated to 'no pain' and 10 equated to 'worst possible pain'. With two wards and 30 patients in each period within a ward, the trial was powered $^{32}$ to detect a difference of 1.65 or more in mean pain intensity scores (a third ward was included to retain all consented patients).

A multimodal analgesic regime that included paracetamol, non-steroidal anti-inflammatory drugs (NSAIDs), long-acting opioids and short-acting opioids (for breakthrough pain) was recommended for all patients.

\section{Secondary outcomes}

Secondary outcomes were interference of pain on activities of daily living measured by items in the American Pain Society Patient Outcome QuestionnaireRevised (APSOQ-R) ${ }^{34}$ on day 3, length of hospital stay (days), function and pain following TKR surgery measured using the Oxford Knee Score (OKS) 35364 weeks after discharge from acute care, overall satisfaction and NET promoter score ${ }^{37}$ measured 4 weeks after discharge from acute care, incidence of deep vein thrombosis (DVT) within 28 days and incidence of readmission to study hospital within 28 days.

\section{Concurrent process evaluation}

Process evaluation was used to assess the conduct of the trial and explore whether the intervention had the intended effect of providing patients with the capability and opportunity to participate in care related to their goals of recovery. The overall objectives of the process evaluation were to determine if there were any differences in patient activation (Patient Activation Measure, ${ }^{38}$ PAM) between intervention and control group patients and, whether patient outcomes related to pain intensity may have been attributed to differences in available (prescribed) and/or administered analgesics between groups.

\section{Randomisation}

Two wards (clusters) were randomly assigned (by the trial statistician) to a sequence of control (A) and intervention (B) periods prior to recruitment of patients and commencement of the trial. A third ward, used as an 'overflow ward' for consented patients who could not be accommodated in the first two wards, received the control condition in each period. At the time of patient recruitment, it was not known to which cluster 


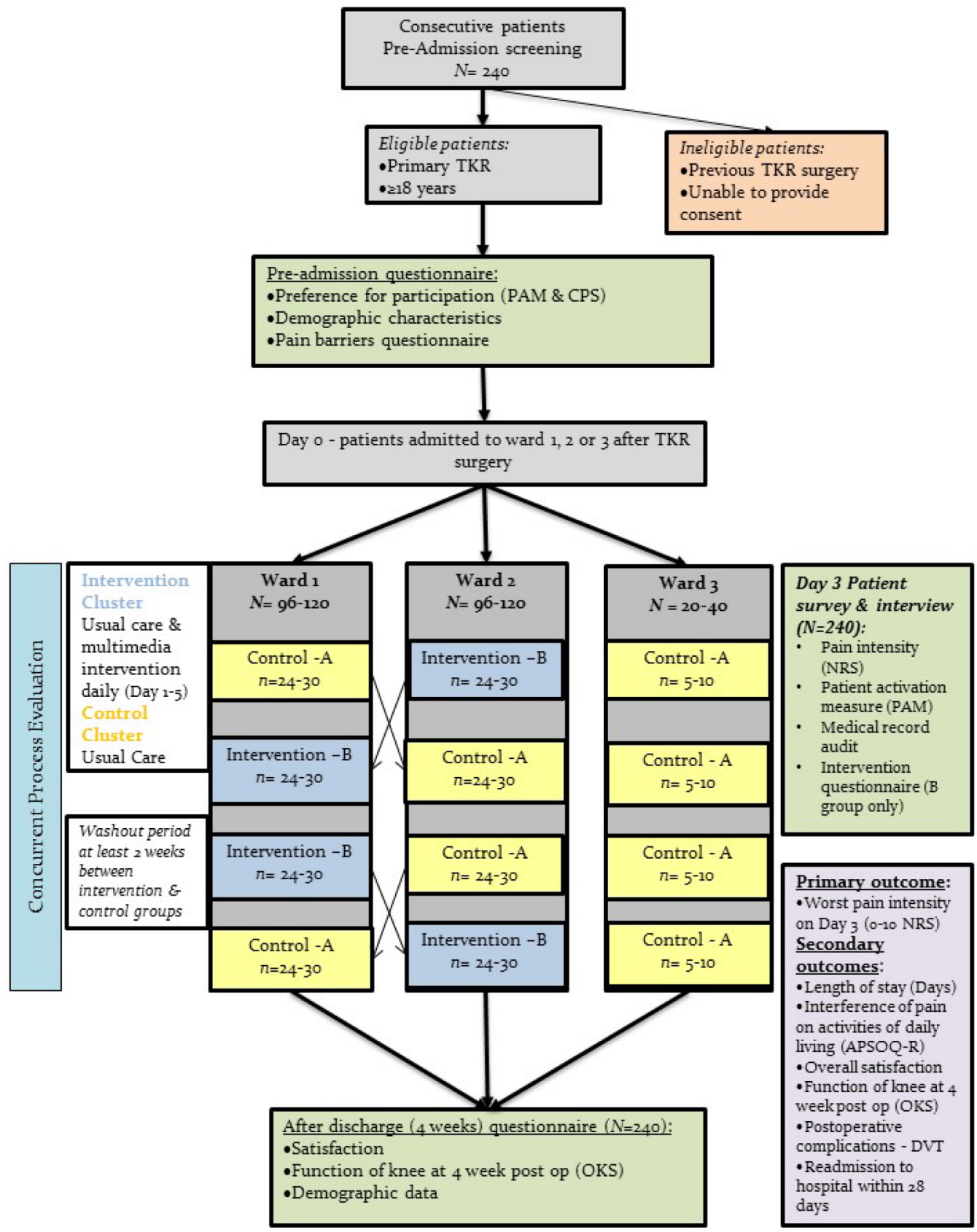

*Legend

A - Intervention cluster

$B$ - Control cluster

TKR - Total Knee Replacement

Figure 1 Study design. APSOQ-R, American Pain Society Patient Outcome Questionnaire—Revised; CPS, Control Preference Scale; DVT, deep vein thrombosis; NRS, Numerical Rating Scale; OKS, Oxford Knee Score.

or period individual patients would be allocated. Allocation of patients to clusters occurred via usual hospital processes of ward allocation post-surgery and was largely dependent on bed availability at the time of surgery. Patient allocation to wards is undertaken centrally by a discrete hospital service and was in no way related to this research project or any persons involved or aware of this research.

\section{Multimedia intervention}

The bedside multimedia intervention known as 'MyStay Total Knee Replacement' (referred to as 
MyStay) was developed through consultation with patients, surgeons, physiotherapists and nurses and review of best available evidence and existing clinical pathways (detailed description of MyStay development-online supplementary material 1). MyStay was presented in a chapter-based format that combined text, sound, graphics and animation and packaged for iPad presentation. It was designed to be both clinician-facilitated and patient self-directed, that is, to be facilitated by clinicians during patient-clinician interactions but also used independently by patients as a stand-alone programme. MyStay had two interacting components: (1) information tailored to each day of recovery to enhance patients' understanding of the goals of recovery and their role in their own recovery, and (2) opportunity for patients to achieve their recovery goals through clinician facilitation.

It was expected that MyStay would facilitate interactions between patients and clinicians about daily goals and plans of care for each day of recovery and provide an opening for patients to discuss their pain management. Nurses in particular were asked to incorporate the intervention at the beginning-of-shift patient assessments by assisting their patients to navigate through the programme, clarify any uncertainties and plan their management together. Physiotherapists were asked to incorporate the exercise animations into physiotherapy sessions. Application of MyStay commenced on day 1 after TKR surgery.

\section{Comparator}

During control periods, throughout and following a wash-out period of 2 weeks, iPads containing MyStay were removed and patients received usual care based on the hospital standard care pathway (online supplementary material 2).

\section{Data collection}

Data were collected at three time points: pre-admission, day 3 postoperatively and 4 weeks following discharge from acute care (table 1).

On day 3, all patients (intervention and control) completed a self-reported questionnaire and participated in a semistructured interview. Concurrent medication chart and medical record audits elicited the type and quantity of analgesics prescribed and administered in the previous 24 hours corresponding to the primary outcome measure of worst (dynamic) pain intensity.

Analgesics were prescribed either as fixed or pro re nata (PRN). Fixed analgesics were administered at set intervals and were not modifiable unless there was a contraindication to their administration; PRN analgesics were administered in response to 'breakthrough' pain (ie, pain that breaks through a fixed analgesic regimen) or in preparation for activities that may exacerbate pain such as physiotherapy or mobilisation.

According to the existing clinical care pathway in all wards, patients were deemed 'eligible for discharge'
Table 1 Measurements and tools used according to data collection periods

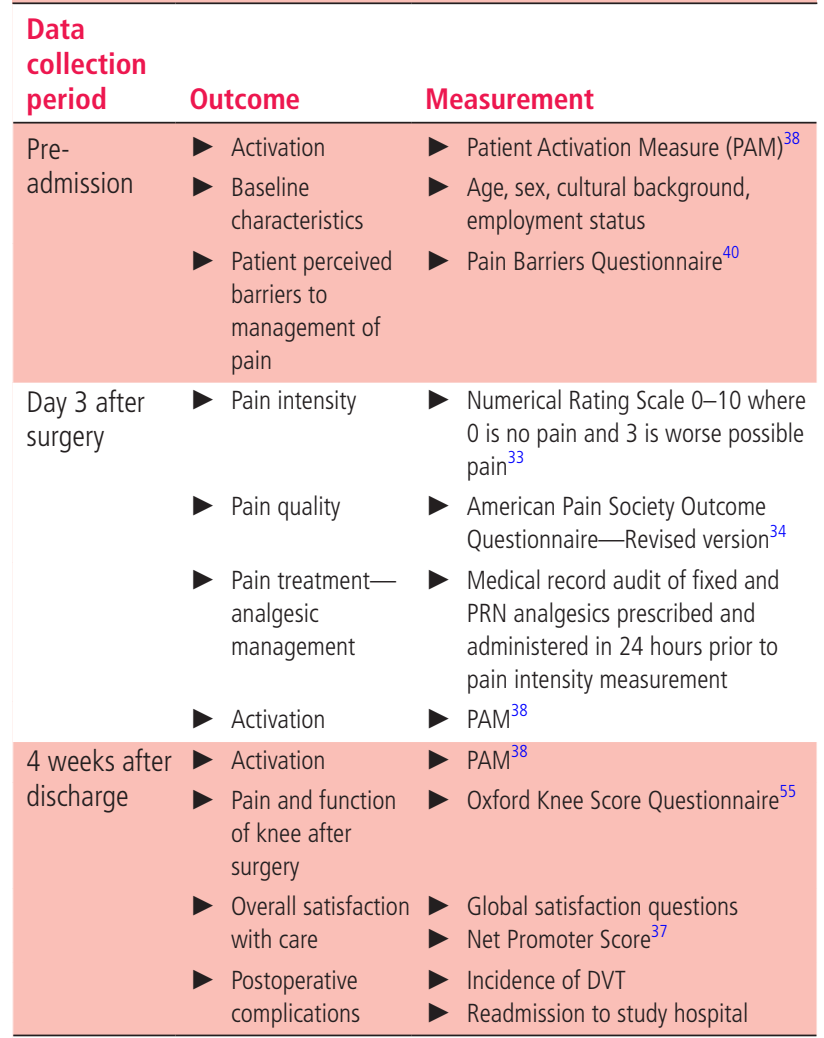

DVT, deep vein thrombosis; PRN, pro re nata.

from acute care when assessed as medically stable, tolerating diet and fluids, walking independently, could safely ascend and descend stairs with the use of a walking aid, demonstrated confidence in attending home exercise programmes and were comfortable with a pain medication regime.

Follow-up questionnaires were administered 4 weeks after discharge via mail.

\section{Statistical analyses}

Quantitative data were analysed using GenStat (V.17) and analyses were independently validated using SPSS V.23. Statistical significance was claimed at $p$ value $<0.05$. Descriptive statistics were used to characterise the study population and any differences between treatment groups and environmental characteristics. For the primary endpoint of pain intensity, a linear mixed model analysis, using the restricted maximum likelihood (REML) method, ${ }^{39}$ was used to calculate the F-test to enable comparison of the means of the groups (intervention vs usual care). The model included random effects for wards, cohorts within wards and patients within cohorts, and fixed effects for period and treatment (control vs intervention). If the period effect was not significant, it was deleted from the mixed model. Other outcome measures such as length of stay (LOS), pain and function following TKR, overall satisfaction, NET promoter, 


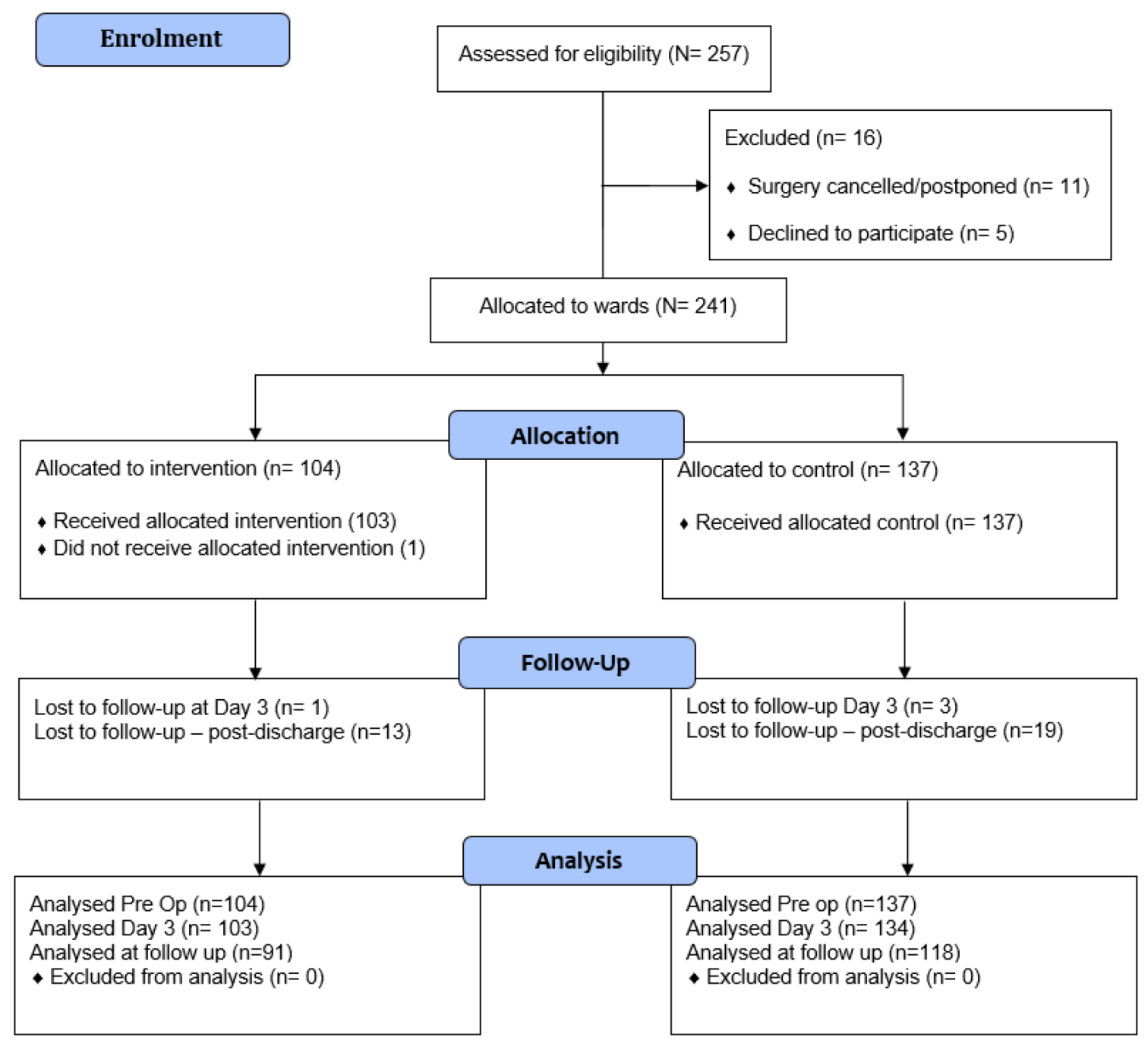

Figure 2 Trial profile.

patient activation, incidence of DVTs and readmission to study hospital were compared between the groups and analyses used a linear mixed model approach and analogous methods developed for binary and categorical data. Analysis was according to intention to treat.

\section{RESULTS}

\section{Patient recruitment}

Between 12 March 2014 and 10 June 2015, of the 257 eligible patients, 241 were recruited (figure 2) either via the hospital pre-admission clinic $(79.6 \%)$ or via mail-out invitations (20.4\%). There was no significant difference in allocation to intervention or control cohorts for patients recruited via either method.

Recruitment ended when the number of participants required for statistical power was reached. Follow-up data collection was completed in September 2015. Data validation and cleaning was conducted by the trial statistician, blinded to groups.
Loss to follow-up

Figure 2 outlines the flow of patients through the trial. One patient, allocated to an intervention period, did not receive the intervention because of a cerebrovascular accident in the early postoperative period. After discharge, $86.7 \%$ patients returned follow-up questionnaires.

\section{Baseline data}

The baseline characteristics of patients are presented in table 2. The mean age of participants was 65.3 (SD 9.8) years in the intervention group and 67.4 (SD $8.7)$ years in the control group $(\mathrm{p}=0.20)$. There were slightly more women $(55.2 \%)$ than men $(44.8 \%)$ in the sample overall, and the proportion of men was lower in the intervention group (38.5\%) than the control group (49.6\%), but this difference was not significant $(\mathrm{p}=0.09)$. Key demographic characteristics were balanced between study periods.

\section{Baseline assessments}

The Pain Barriers Questionnaire (BQ) ${ }^{40}$ and $\mathrm{PAM}^{41}$ were completed prior to admission by all patients. 
Table 2 Baseline characteristics of the intention-to-treat population

\begin{tabular}{|c|c|c|}
\hline & $\begin{array}{l}\text { Intervention group } \\
(\mathrm{n}=104)\end{array}$ & $\begin{array}{l}\text { Control group } \\
(n=137)\end{array}$ \\
\hline Characteristics & Mean (SD) & Mean (SD) \\
\hline Age (years) & $65.25(9.77)$ & $67.42(8.7)$ \\
\hline Sex & $\mathrm{n}(\%)$ & $\mathrm{n}(\%)$ \\
\hline Male & $40(38.5 \%)$ & $68(49.6 \%)$ \\
\hline Female & $64(61.5 \%)$ & $69(50.4 \%)$ \\
\hline \multicolumn{3}{|l|}{ Living arrangements } \\
\hline Living communally & $88(84.6 \%)$ & $109(79.6 \%)$ \\
\hline Living alone & $16(15.4 \%)$ & $28(20.4 \%)$ \\
\hline \multicolumn{3}{|l|}{ Marital status } \\
\hline Partnered & $84(80.8 \%)$ & $106(77.4 \%)$ \\
\hline Not partnered & $10(9.6 \%)$ & $18(11.6 \%)$ \\
\hline Widowed & $10(9.6 \%)$ & $13(9.5 \%)$ \\
\hline \multicolumn{3}{|l|}{ Country of birth } \\
\hline Australia & $76(73.1 \%)$ & $101(73.7 \%)$ \\
\hline UK & $11(10.6 \%)$ & $10(7.3 \%)$ \\
\hline Other & $8(7.7 \%)$ & $11(8.0 \%)$ \\
\hline Europe & $6(5.8 \%)$ & $10(7.3 \%)$ \\
\hline Asia & $2(1.9 \%)$ & $3(2.2 \%)$ \\
\hline New Zealand & $1(1.0 \%)$ & $2(1.5 \%)$ \\
\hline \multicolumn{3}{|c|}{ Language spoken at home (primary) } \\
\hline English & $102(98.0 \%)$ & $130(96.3 \%)$ \\
\hline Italian & $1(1.0 \%)$ & $2(1.5 \%)$ \\
\hline Mandarin & $0(0 \%)$ & $1(0.7 \%)$ \\
\hline Greek & $0(0 \%)$ & $1(0.7 \%)$ \\
\hline Other & $1(1.0 \%)$ & $3(2.2 \%)$ \\
\hline \multicolumn{3}{|c|}{ Employment status pre-admission } \\
\hline Retired & $52(50.0 \%)$ & $76(55.5 \%)$ \\
\hline Full time & $24(23.1 \%)$ & $28(20.4 \%)$ \\
\hline Part time/casual & $16(15.4 \%)$ & $25(18.2 \%)$ \\
\hline Unemployed & $7(6.7 \%)$ & $3(2.2 \%)$ \\
\hline Other & $5(4.8 \%)$ & $5(3.6 \%)$ \\
\hline \multicolumn{3}{|l|}{ Recruitment method } \\
\hline Pre-admission clinic & $79(76 \%)$ & $113(82.5 \%)$ \\
\hline Mail-out & $25(24 \%)$ & $24(17.5 \%)$ \\
\hline
\end{tabular}

There were no significant differences in the mean scores for the BQ between groups (intervention group $\mathrm{M}=16.1$ vs control group $\mathrm{M}=15.6, \mathrm{t}=0.71$, $\mathrm{p}=0.48$ ). Pre-admission, patients in both groups were found to have a high level of activation (levels 3 and 4) according to the PAM, indicating an understanding of their role in maintaining their health and perceived capability to fulfil that role (intervention group 79\% vs control group $74 \%, \mathrm{p}=0.09)$.

\section{Primary outcome}

The mean worst pain scores, measured on day 3 using the NRS, were 6.05 (SEM 0.33) (intervention group) and 7.05 (SEM 0.28) (control group) (mean difference
$(\mathrm{I}-\mathrm{C})=-1.01,95 \% \mathrm{CI}-1.94$ to $-0.08, \mathrm{p}=0.04)$. The period effect was not significant $(\mathrm{p}=0.61)$ and the estimated components of variance were $0.05,0.14$ and 5.56 for wards, cohorts within wards and patients within cohorts, respectively. The percentages of patients with severe pain (score $\geq 7$ ) were $43.7 \%$ intervention group versus $64.2 \%$ control group $(p=0.002$; generalised linear mixed model Wald test, $\mathrm{p}=0.049$ ). In an unplanned, supplementary analysis that excluded all 41 patients in the overflow ward, the mean worst pain scores were 6.03 (SEM 0.38) (intervention group) and 6.96 (SEM 0.39) (control group) (mean difference $95 \% \mathrm{CI}-2.13$ to $0.27, \mathrm{p}=0.10)$.

In an additional unplanned analysis adjusted for administered PRN oxycodone (Endone), inclusion of the oxycodone covariate in the REML analysis was almost statistically significant $(\mathrm{p}=0.05)$ and a $1 \mathrm{mg}$ increase in dose was associated with a 0.03 increase in day-3 reported pain (NRS). The difference in the adjusted means of the treatment arms remained significant: mean difference $(95 \%$ CI -2.06 to -0.25 , $\mathrm{p}=0.02$ ). There was no evidence of an interaction between the oxycodone covariate and the treatment $(\mathrm{p}=0.41)$.

\section{Secondary outcomes}

Secondary outcome analyses (APSOQ-R) are presented in online supplementary material 3 . Patients in the intervention group perceived that they had received more pain relief in the previous 24 hours $(M=7.67$ vs $M=7.07,95 \%$ CI -0.003 to $1.194, p=0.05)$. Significantly more patients in the intervention group than the control group reported using deep breathing as a method to relieve pain $\left(82.2 \%\right.$ vs $\left.68 \%, \chi^{2}=5.53, p=0.02\right)$.

There was a significant reduction in LOS for the intervention group; intervention group 5.29 days vs control group 6.29 days $(95 \%$ CI -0.05 to -1.94 , $\mathrm{p}=0.04$ ). One patient in the intervention group was discharged prior to day 3; this patient was sent to in-hospital rehabilitation on day 2 following surgery. None of the control group patients were discharged from acute care prior to day 3 .

There was no difference between groups in terms of those discharged directly home compared with a rehabilitation facility. Most patients $(86.3 \%)$ were discharged to in-patient rehabilitation. In addition, there was no difference between patients discharged home versus rehabilitation in terms of acute care length of stay.

\section{Patient activation}

There was no significant difference in activation between groups when measured at baseline $\left(\chi^{2}=6.41\right.$, $\mathrm{p}=0.09)$. On day 3 , a significantly higher proportion of patients in the intervention group reported level 4 activation $\left(45.1 \%\right.$ vs $\left.27.1 \%, \chi^{2}=8.47, \mathrm{p}=0.04\right)$. The number of control group patients with activation 
Table 3 Prescribed fixed and PRN analgesics by group

\begin{tabular}{|c|c|c|c|}
\hline \multirow{3}{*}{$\begin{array}{l}\text { Analgesic } \\
\text { (fixed) }\end{array}$} & \multicolumn{3}{|l|}{ Prescribed } \\
\hline & \multirow{2}{*}{$\frac{\text { Control }}{n(\%)^{*}}$} & \multirow{2}{*}{$\begin{array}{l}\text { Intervention } \\
\mathrm{n}(\%)\end{array}$} & \multirow[t]{2}{*}{$P$ value } \\
\hline & & & \\
\hline \multicolumn{4}{|l|}{ NSAIDs } \\
\hline Ibuprofen & $18(13.1 \%)$ & $15(14.4 \%)$ & 0.77 \\
\hline Celecoxib & $19(13.9 \%)$ & $16(15.4 \%)$ & 0.74 \\
\hline Naproxen & $8(5.8 \%)$ & $12(11.5 \%)$ & 0.11 \\
\hline Meloxicam & $32(23.4 \%)$ & $27(26.0 \%)$ & 0.64 \\
\hline Paracetamol & 97 (70.8\%) & $84(80.8 \%)$ & 0.08 \\
\hline Pregabalin & $72(52.6 \%)$ & $64(61.5 \%)$ & 0.16 \\
\hline Oxycodone SR & $38(27.7 \%)$ & $31(29.8 \%)$ & 0.73 \\
\hline $\begin{array}{l}\text { Oxycodone- } \\
\text { naloxone }\end{array}$ & $66(48.2 \%)$ & 37 (35.6\%) & 0.05 \\
\hline \multicolumn{4}{|l|}{ Analgesic (PRN) } \\
\hline Morphine & $62(45.3 \%)$ & $48(46.2 \%)$ & 0.89 \\
\hline Oxycodone & $131(95.6 \%)$ & $101(97.1 \%)$ & 0.54 \\
\hline Tramadol & $62(45.3 \%)$ & $35(33.7 \%)$ & 0.07 \\
\hline
\end{tabular}

scores at level 3 or 4 reduced from $74 \%$ at baseline to $53 \%$ on day 3 . Activation in the intervention group patients also declined but not to the same degree; from $79 \%$ patients at level 3 or 4 at baseline to $64 \%$ on day 3.

Four weeks after discharge from acute care, patients' activation levels returned to those at pre-admission. For the intervention group, $82 \%$ indicated level 3 or 4 activation versus $74 \%$ control group patients on follow-up. There was no significant difference between groups in patient activation measured at follow-up $(\mathrm{p}=0.56)$.

\section{Analgesic management}

In relation to processes of care, the prescription and administration of both fixed and PRN analgesics for the 24 hours preceding the day 3 pain score were extracted from all patients' charts. There was no significant difference between groups in terms of prescribed regular and PRN analgesics. Tables 3 and 4 outline prescribed and administered fixed and PRN analgesics by treatment group, respectively. There were no differences in prescriptions for paracetamol, NSAIDs, adjuvant medicines or opioids between groups. Overall, $5.8 \%$ of patients indicated an allergy to NSAIDs and were excluded from these analyses.

The most commonly prescribed and administered PRN strong opioid was oxycodone (Endone) with most patients (96.3\%) receiving at least one dose during the 24-hour audit period (table 4). Endone was administered as an oral tablet and the total administered dose over 24 hours ranged from 2.5 to $30 \mathrm{mg}$. There was a difference between treatment groups in the mean
Table 4 Administered fixed and PRN analgesics by group

\begin{tabular}{|c|c|c|c|}
\hline \multirow{3}{*}{$\begin{array}{l}\text { Analgesic } \\
\text { (fixed) }\end{array}$} & \multicolumn{3}{|c|}{ Administered (mg) } \\
\hline & \multirow{2}{*}{$\begin{array}{l}\text { Control } \\
M(S D)^{*}\end{array}$} & \multirow{2}{*}{$\begin{array}{l}\text { Intervention } \\
\mathrm{M}(\mathrm{SD})\end{array}$} & \multirow[t]{2}{*}{$P$ value } \\
\hline & & & \\
\hline \multicolumn{4}{|l|}{ NSAIDs } \\
\hline Ibuprofen & $966.7(330.8)$ & $1040.0(364.1)$ & 0.55 \\
\hline Celecoxib & $173.7(56.2)$ & $206.2(85.4)$ & 0.19 \\
\hline Naproxen & 718.7 (338.2) & $526.5(400.6)$ & 0.40 \\
\hline Meloxicam & $13.1(3.7)$ & $11.0(6.0)$ & 0.10 \\
\hline Paracetamol & 3236.1 (933.4) & $3250.0(1008.6)$ & 0.92 \\
\hline Pregabalin & $158.3(82.8)$ & $162.1(58.1)$ & 0.76 \\
\hline Oxycodone SR & $22.4(13.6)$ & $25.8(14.5)$ & 0.32 \\
\hline $\begin{array}{l}\text { Oxycodone- } \\
\text { naloxone }\end{array}$ & $19.9(11.0)$ & $20.5(7.8)$ & 0.77 \\
\hline \multicolumn{4}{|l|}{ Analgesic (PRN) } \\
\hline Morphine & $1.49(4.1)$ & $1.25(3.1)$ & 0.74 \\
\hline Oxycodone & $10.8(12.0)$ & $16.1(12.9)$ & $<0.001$ \\
\hline Tramadol & $64.7(97.3)$ & $61.2(99.67)$ & 0.86 \\
\hline \multicolumn{4}{|c|}{$\begin{array}{l}\text { *Zero doses (prescribed but not administered) are excluded from } \\
\text { calculation of the mean in milligrams (M) and SD. } \\
\text { NSAID, non-steroidal anti-inflammatory drug; PRN, pro re nata; SR, } \\
\text { sustained release. }\end{array}$} \\
\hline
\end{tabular}

daily amount (mg) of oxycodone administered PRN (intervention group $\mathrm{M}=16.1$ vs control group 10.8 , $\mathrm{t}=3.23, \mathrm{p}=0.001$ ) (table 4). While the interaction between treatment groups and subgroups of patients categorised by pain score $(0-3,4-6$ and $7-10)$ was not significant $(p=0.29)$, there was a trend $(p=0.002)$ for oxycodone administered PRN to increase across the pain groups and a significant difference between the treatments was noticed in the highest $(7-10)$ pain group: intervention $(\mathrm{M}=21.2, \mathrm{SD}=13.5 \mathrm{mg})$ and control $(\mathrm{M}=11.9, \mathrm{SD}=12.9 \mathrm{mg})$ groups $(\mathrm{p}=0.004)$.

\section{Patient follow-up}

Intervention group patients had a mean OKS of 19.9 and control group patients 21.3 four weeks post-surgery; this difference was not significant $(95 \% \mathrm{CI}-5.78$ to $2.80, \mathrm{p}=0.44$ ).

Intervention group patients reported higher mean satisfaction with care received of 9.26 versus 8.58 control group patients (95\% CI 1.09 to 0.219 , $\mathrm{p}=0.01$ ). Intervention group patients were also more likely to 'recommend the health service to a family or friend' (NET promoter score) with a mean score of 9.27 versus 8.67 ( $95 \% \mathrm{CI} 0.13$ to $1.07, \mathrm{p}=0.02)$. The intervention group also had a higher percentage of promoters $(81.3 \%)$ compared with the control group $(66.9 \%)\left(\chi^{2}[2, \mathrm{~N}=209]=8.80, \mathrm{p}=0.01\right)$.

Eight $(3.3 \%)$ patients developed a DVT while inpatients or presented to the study hospital within 28 days of discharge. Of these, six patients were in the intervention group and two were in the control group $(p=0.06)$. Six $(2.5 \%)$ patients were readmitted to hospital within 28 days of discharge from hospital for 
any reason; three in the intervention and three in the control group $(p=0.73)$.

\section{DISCUSSION}

Our results show that the MyStay intervention, designed to enhance patient participation, was effective in reducing patients' reported pain intensity on day 3 after TKR surgery when compared with standard care. Although patients in both groups reported high levels of dynamic pain on day 3 following surgery (suggesting that pain management overall was suboptimal), ${ }^{42}$ intervention group patients reported lower worst pain scores indicating that they experienced lower levels of dynamic pain. Patients who received the intervention also had a lower length of stay in acute care, higher overall satisfaction with the care they had received, and were more likely to recommend the health service for similar surgery to family and friends. There were no observed differences in interference of pain on activities of daily living (APSOQ-R), knee pain and functioning (OKS) 4 weeks after discharge, incidence of DVTs or readmission to the study hospital.

The clinical significance of these results is the evidence of the impact of patient participation on patient-reported and organisational outcomes in acute care environments. Prior to this study, interventions designed to facilitate patient participation in acute care had failed to show effects other than higher patient satisfaction. ${ }^{43-46}$

While the significant reduction (1.01) in mean pain scores may seem small, it corresponds to a 'medium' effect size (Cohen's d) of 0.42 and it is approximately one-third of the IQR of the observed scores and is therefore of clinical relevance. Furthermore, whereas $64 \%$ of control patients had a day-3 score $\geq 7$, with MyStay $44 \%$ of patients had a day-3 score $\geq 7$. In some patient populations, ' 7 ' is regarded as the cut-off for severe pain ${ }^{47}$ so the MyStay intervention produced a non-trivial reduction in the percentage of patients experiencing severe pain. Patients in the intervention group received significantly higher amounts of PRN oxycodone. While that may explain the lower reported worse pain intensity scores, unplanned post hoc analyses failed to show a significant interaction between PRN oxycodone dose and treatment group. Patients receiving MyStay were also more likely to use non-pharmacological methods to manage pain. We need a better understanding of the ways in which patient participation affects pain experience and patients' influence on the care they receive. We can conclude, however, that the MyStay intervention as a treatment policy has a clinically important effect on the occurrence of severe pain.

Reasons for differences in acute LOS can be multidimensional and may depend on the age and demographic characteristics of the patient population, readiness of the patient for discharge and the availability of beds in rehabilitation facilities. ${ }^{48}$ The observed reduction in LOS may not be reproducible in the future where the LOS in acute care is continually decreasing through enhanced recovery pathways. ${ }^{49}$ Although enhanced recovery pathways are commonly used internationally, they are not widely used in Australia to date. ${ }^{5152}$ On average, data from 2016 to 2017 indicate that patients following TKR in Australia spend 4.7 days (range, 3.6-8.3 days) in hospital. ${ }^{53}$ There were no changes to the Care Pathways or TKR practice by the surgeons during the study period. The reduction in hospital LOS observed in this study suggests that a relatively low-cost, clinician-facilitated MyStay multimedia intervention at the bedside that provided patients with the necessary information and the opportunity to engage with clinicians increased patients' engagement in mobility and exercise to maximise function and knee flexion, and hence 'readiness for discharge'. The findings provide 'proof of concept' that patient participation can improve outcomes other than patient satisfaction alone and the benefits of patient participation may extend to rehabilitation or home if patients are discharged early.

Further evidence suggesting that MyStay was effective in engaging patients in their recovery were findings relating to the activation scores and satisfaction with care. Prior to admission, the majority of patients had relatively high activation scores indicating that they felt they had the necessary skills and knowledge to care for themselves. There was no difference between intervention $(79 \%$ at level 3 or 4 ) and control groups ( $74 \%$ at level 3 or 4$)$ prior to admission to hospital. On day 3 after surgery, although there was a reduction in the proportion of patients at level 3 and 4 activation in both groups, this reduction was most marked in control group patients. There was a $20 \%$ decrease in the number of control group patients with level 3 or 4 activation compared with baseline, and the difference between intervention and control group patients at this level was significant. Patient activation measures returned to baseline measures for both groups 4 weeks after surgery. These findings highlight the impact of acute illness and acute care environments on patients' perceived ability to manage their healthcare needs and the need for, and potential effectiveness of, interventions to moderate these impacts.

Patients exposed to the intervention had a significantly higher overall satisfaction with their acute care experience and a higher NET promoter score. Although there are well-known limitations in the measurement of patient satisfaction, ${ }^{25-27}$ the consistency of higher satisfaction with other patient-reported outcomes such as the NET promoter score ${ }^{37}$ and lower reported pain intensity supports an interpretation of an intervention effect on satisfaction.

Failure to obtain an OKS preoperatively meant that we could not evaluate differences in changes 
in knee function at follow-up. Further limitations may include the lack of blinding of the intervention among ward nurses, patients and data collectors and could have introduced bias. Blinding in this type of intervention was not possible because the iPads were visible and patients would often refer to the MyStay. To mitigate the risk of bias, validated outcome questionnaires were used. Data collectors extracting medical record audit data and the statistician who conducted the analysis were blinded to group. A robust research methodology was used to overcome the limitations associated with conducting a single-site $\operatorname{study}^{54}$; however, the generalisability of our findings to other health service settings needs further investigation. The inclusion in the analyses of data gathered from consented patients allocated to the overflow ward, which itself received a fixed sequence consisting of the control condition in all four periods, could be criticised for being susceptible to an unknown allocation bias; however, in a supplementary analysis of the primary endpoint, which excluded these patients, the observed effect was similar in magnitude, but given the $17 \%$ reduction in the total sample size, it was no longer statistically significant at the conventional 5\% level.

Creating an opportunity for patient participation without placing additional burden on clinicians and patients in this context was considered critical because implementing a shared tool has the risk of adding to the burden of care rather than facilitating it. Time spent orientating patients to the technology was approximately 5 to $10 \mathrm{~min}$ initially (day 1 ), then 2 to $5 \mathrm{~min}$ per day with individual patients. It is concluded, therefore, that the MyStay intervention can be incorporated into everyday routine care despite the acuity of the environment, and the time required for clinicians to apply (not facilitate) the programme is low and feasible. The MyStay programme provides patients with an alternative and complementary source of information related to their recovery that is usually highly reliant on clinicians and often limited to "what is important now' rather than what the patient wants or needs to know.

Our findings contribute to the evolving understanding of the role of patient participation in acute care environments and the use of multimedia technology as a tool for facilitating patient-clinician interactions. We have shown that a simple and easily implementable intervention such as MyStay facilitated patient participation in their care after surgery and improved outcomes. These findings would be strengthened by replication in other acute healthcare settings; however, our findings support the use of facilitated patient engagement interventions in postoperative recovery after TKR.
Author affiliations

${ }^{1}$ Faculty of Health, School of Nursing and Midwifery, Centre for Quality and Safety Research, Deakin University, Geelong, Victoria, Australia

${ }^{2}$ Department of Surgery, Epworth Healthcare, The University of Melbourne, Melbourne, Victoria, Australia

${ }^{3}$ Faculty of Medicine Nursing and Health Sciences, Monash University, Clayton, Victoria, Australia

${ }^{4}$ Faculty of Health, School of Nursing and Midwifery, Deakin University, Geelong, Victoria, Australia

${ }^{5}$ Faculty of Health, School of Nursing and Midwifery, Centre for Quality and Safety Research, Epworth Partnership, Deakin University, Geelong, Victoria, Australia

Acknowledgements The authors acknowledge and thank the associate editors and reviewers for their helpful comments.

Contributors JM, RdS, BR, AFH, PML, JR and MB conceived the study and designed the trial. MB supervised the conduct of the trial and data collection. JM collected, analysed the data and drafted the manuscript. JR was responsible for secondary analysis of the data. All authors contributed substantially to manuscript revision. JM completed the final draft, submitted the manuscript and takes responsibility for the paper as a whole.

Funding The Norman Beischer Medical Research Foundation provided funding for the MyStay development.

Competing interests None declared.

\section{Patient consent for publication Obtained.}

Ethics approval Approval to conduct this research was received from the University Human Research and Ethics Committee (approval no. 2013-195) and the hospital where the data were collected (approval no. 598-13).

Provenance and peer review Not commissioned; externally peer reviewed.

Open access This is an open access article distributed in accordance with the Creative Commons Attribution Non Commercial (CC BY-NC 4.0) license, which permits others to distribute, remix, adapt, build upon this work noncommercially, and license their derivative works on different terms, provided the original work is properly cited, appropriate credit is given, any changes made indicated, and the use is noncommercial. See: http://creativecommons.org/licenses/by-nc/4. $0 /$

\section{REFERENCES}

1. World Health Organisation. Declaration of Alma-Ata, 1978. Available: http://www.who.int/hpr/NPH/docs/declaration_ almaata.pdf [Accessed February 22 2010].

2. Keat R, Whiteley N, Abercrombie N. The authority of the consumer. Taylor \& Francis, 1994.

3. Longtin Y, Sax H, Leape LL, et al. Patient participation: current knowledge and applicability to patient safety. Mayo Clin Proc 2010;85:53-62.

4. Lorig KR, Sobel DS, Stewart AL, et al. Evidence suggesting that a chronic disease self-management program can improve health status while reducing hospitalization: a randomized trial. Med Care 1999;37:5-14.

5. Bourbeau J, Julien M, Maltais F, et al. Reduction of hospital utilization in patients with chronic obstructive pulmonary disease: a disease-specific self-management intervention. Arch Intern Med 2003;163:585-91.

6. Shively MJ, Gardetto NJ, Kodiath MF, et al. Effect of patient activation on self-management in patients with heart failure. $J$ Cardiovasc Nurs 2013;28:20-34.

7. Bastiaens H, Van Royen P, Pavlic DR, et al. Older people's preferences for involvement in their own care: a qualitative study in primary health care in 11 European countries. Patient Educ Couns 2007;68:33-42. 
8. Doherty C, Doherty W. Patients' preferences for involvement in clinical decision-making within secondary care and the factors that influence their preferences. J Nurs Manag 2005;13:119-27.

9. Sainio C, Lauri S, Eriksson E. Cancer patients' views and experiences of participation in care and decision making. Nurs Ethics 2001;8:97-113.

10. Belcher VN, Fried TR, Agostini JV, et al. Views of older adults on patient participation in medication-related decision making. J Gen Intern Med 2006;21:298-303.

11. Larsson IE, Sahlsten MJM, Segesten K, et al. Patients' perceptions of barriers for participation in nursing care. Scand J Caring Sci 2011;25:575-82.

12. Henderson S. Power imbalance between nurses and patients: a potential inhibitor of partnership in care. J Clin Nurs 2003;12:501-8.

13. Aasen EM, Kvangarsnes M, Heggen K. Perceptions of patient participation amongst elderly patients with end-stage renal disease in a dialysis unit. Scand J Caring Sci 2012;26:61-9.

14. Hibbard JH, Cunningham PJ. How engaged are consumers in their health and health care, and why does it matter? Res Brief 2008;(8):1-9.

15. Greene J, Hibbard JH. Why does patient activation matter? An examination of the relationships between patient activation and health-related outcomes. J Gen Intern Med 2012;27:520-6.

16. O'Leary KJ, Killarney A, Hansen LO, et al. Effect of patientcentred bedside rounds on hospitalised patients' decision control, activation and satisfaction with care. BMJ Qual Saf 2016;25:921-8.

17. Ernst J, Kuhnt S, Schwarzer A, et al. The desire for shared decision making among patients with solid and hematological cancer. Psychooncology 2011;20:186-93.

18. Brom L, Hopmans W, Pasman HRW, et al. Congruence between patients' preferred and perceived participation in medical decision-making: a review of the literature. BMC Med Inform Decis Mak 2014;14.

19. McMurray A, Chaboyer W, Wallis M, et al. Patients' perspectives of bedside nursing handover. Collegian 2011;18:19-26.

20. Weingart SN, Zhu J, Chiappetta L, et al. Hospitalized patients' participation and its impact on quality of care and patient safety. Int J Qual Health Care 2011;23:269-77.

21. Singh JA. Epidemiology of knee and hip arthroplasty: a systematic review. Open Orthop J 2011;5:80-5.

22. Carr AJ, Robertsson O, Graves S, et al. Knee replacement. Lancet 2012;379:1331-40.

23. Guerra ML, Singh PJ, Taylor NF. Early mobilization of patients who have had a hip or knee joint replacement reduces length of stay in hospital: a systematic review. Clin Rehabil 2015;29:844-54.

24. Kehlet H. Fast-track hip and knee arthroplasty. Lancet 2013;381:1600-2.

25. Gerbershagen HJ, Aduckathil S, van Wijck AJM, et al. Pain intensity on the first day after surgery: a prospective cohort study comparing 179 surgical procedures. Anesthesiology 2013;118:934-44.

26. Fletcher D, Fermanian C, Mardaye A, et al. A patient-based national survey on postoperative pain management in France reveals significant achievements and persistent challenges. Pain 2008;137:441-51.

27. Coulter A, Safran D, Wasson JH. On the language and content of patient engagement. J Ambul Care Manage 2012;35:78-9.
28. Doherty C, Stavropoulou C. Patients' willingness and ability to participate actively in the reduction of clinical errors: a systematic literature review. Soc Sci Med 2012;75:257-63.

29. Cornoiu A, Beischer AD, Donnan L, et al. Multimedia patient education to assist the informed consent process for knee arthroscopy. ANZ J Surg 2011;81:176-80.

30. Farrell EH, Whistance RN, Phillips K, et al. Systematic review and meta-analysis of audio-visual information AIDS for informed consent for invasive healthcare procedures in clinical practice. Patient Educ Couns 2014;94:20-32.

31. Nehme J, El-Khani U, Chow A, et al. The use of multimedia consent programs for surgical procedures: a systematic review. Surg Innov 2013;20:13-23.

32. McDonall J, de Steiger R, Reynolds J, et al. Patient participation in postoperative care activities in patients undergoing total knee replacement surgery: Multimedia Intervention for Managing patient Experience (MIME). study protocol for a cluster randomised crossover trial. BMC Musculoskelet Disord 2016;17.

33. Hartrick CT, Kovan JP, Shapiro S. The numeric rating scale for clinical pain measurement: a ratio measure? Pain Pract 2003;3:310-6.

34. Gordon DB, Polomano RC, Pellino TA, et al. Revised American Pain Society patient outcome questionnaire (APSPOQ-R) for quality improvement of pain management in hospitalized adults: preliminary psychometric evaluation. $J$ Pain 2010;11:1172-86.

35. Dawson J, Fitzpatrick R, Murray D, et al. Questionnaire on the perceptions of patients about total knee replacement. $J$ Bone Joint Surg Br 1998;80:63-9.

36. Murray DW, Fitzpatrick R, Rogers K, et al. The use of the Oxford hip and knee scores. J Bone Joint Surg Br 2007;89B:1010-4.

37. Reichheld FF. The one number you need to grow. Harv Bus Rev 2003;81:46-55.

38. Hibbard JH, Stockard J, Mahoney ER, et al. Development of the patient activation measure (PAM): Conceptualizing and measuring activation in patients and consumers. Health Service Research 2004;39:1005-26.

39. Payne R, Welham S, Simon H. A guide to REML in Genstat ${ }^{\circledR}$. 19th Edition. Hertfordshire, UK VSN International: Hemel Hempstead, 2017.

40. Gunnarsdottir S, Donovan HS, Serlin RC, et al. Patient-related barriers to pain management: the Barriers Questionnaire II (BQ-II). Pain 2002;99:385-96.

41. Hibbard JH, Mahoney ER, Stockard J, et al. Development and testing of a short form of the patient activation measure. Health Serv Res 2005;40:1918-30.

42. Wilson RA, Watt-Watson J, Hodnett E, et al. A randomized controlled trial of an individualized preoperative education intervention for symptom management after total knee arthroplasty. Orthop Nurs 2016;35:20-9.

43. Cook DJ, Manning DM, Holland DE, et al. Patient engagement and reported outcomes in surgical recovery: effectiveness of an e-Health platform. J Am Coll Surg 2013;217:648-55.

44. Dykes PC, Stade D, Chang F, et al. Participatory design and development of a patient-centered toolkit to engage hospitalized patients and care partners in their plan of care. AMIA Annu Symp Proc 2014;2014:486-95.

45. O'Leary KJ, Lohman ME, Culver E, et al. The effect of tablet computers with a mobile patient portal application on hospitalized patients' knowledge and activation. J Am Med Inform Assoc 2016;23:159-65. 


\section{Original research}

46. Vawdrey DK, Wilcox LG, Collins SA, et al. A tablet computer application for patients to participate in their hospital care. AMIA Annu Symp Proc 2011;2011:1428-35.

47. Boonstra AM, Stewart RE, Köke AJA, et al. Cut-off points for mild, moderate, and severe pain on the numeric rating scale for pain in patients with chronic musculoskeletal pain: variability and influence of sex and catastrophizing. Front Psychol 2016;7.

48. Frost P. Hospital Performance: Length of Stay-Victorian Auditor-General's Report; 2016.

49. Eckersley P, Heneghan J, Coughlan L. Introduction of 'Enhanced Recovery' to patients undergoing elective total hip and knee replacement surgery. Physiotherapy 2017;103:e25-6.

50. Soffin EM, YaDeau JT. Enhanced recovery after surgery for primary hip and knee arthroplasty: a review of the evidence. $\mathrm{Br}$ J Anaesth 2016;117(suppl 3):iii62-72.
51. Gwynne-Jones DP, Martin G, Crane C. Enhanced recovery after surgery for hip and knee replacements. Orthop Nurs 2017;36:203-10.

52. Christelis N, Wallace S, Sage CE, et al. An enhanced recovery after surgery program for hip and knee arthroplasty. Med J Aust 2015;202:363-8.

53. Welfare AIoHa, Health services series: admitted patient care: Australian hospital statistics. Web update: average length of stay in 2014-2015, 2015-2016 and 2016-17. Canberra Australian Institute of Health and Welfare; 2018.

54. Bellomo R, Warrillow SJ, Reade MC. Why we should be wary of single-center trials. Crit Care Med 2009;37:3114-9.

55. Dunbar MJ, Robertsson O, Ryd L, et al. Translation and validation of the Oxford-12 item knee score for use in Sweden. Acta Orthop Scand 2000;71:268-74. 